\title{
EDITOR'S INTRODUCTION TO SPECIAL ISSUE ON INDUSTRIAL ORGANIZATION
}

\author{
By REIKO AOKI $\uparrow$ and LUIS CABRAL $\$, \S$ \\ $\dagger$ Japan Fair Trade Commission $\$$ New York University §CEPR
}

When we were asked to edit this Japanese Economic Review special issue on industrial organisation, we thought of it as an opportunity to promote a related initiative on industrial organisation taking place in the region: the Asia-Pacific Industrial Organization Society (APIOS) (http://apios.org.au).

The society emerged out of a conference held in Melbourne in 2017, the first AsiaPacific Industrial Organization Conference. The conference's success led its organisers to convene a second edition (Auckland 2018) and create a society (APIOS) to function as a governing body overseeing the newly created annual conference. The next meeting will take place in Tokyo as this special issue sees the light of day. After that, APIOC is expected to take place in Singapore in 2020.

The present issue is based, broadly speaking, on presentations made at APIOC 2017 and APIOC 2018. The conferences included theory and empirical presentations, as well as policy sessions, frequently with an Asia-Pacific focus.

One hope is that APIOC will present an opportunity for economists to exchange ideas not only in the form of research but also in terms of public policy and advocacy contributions.

This present issue reflects this view. In addition to forays into specific industry studies (Cabral, Igami and Subrahmanyam, Isogawa and Ohashi), we have papers that propose new theoretical frameworks (Chen and Shum, White, Martin, Loertscher and Marx, Garret and Awaya), empirical methods (Hidalgo and Sovinsky, Gil, Kim and Zanarone), as well as a fundamental economic approach to public policy (Jenny).

All in all, we hope this special issue provides a sample of current work in the field of industrial organisation, as well as a "call for interest" in a newly created society and conference. 